on cerebral blowd flow and metabolism in the primate. $\mathcal{f}$ Cereh Blood Flow Metabol 1981;1:349-56.

10 Harris RJ, Branston NM, Symon L, Bavhan M, Watson A. The effects of a calcium antagonist, nimodipine, upon physiological responses of the cerebral vasculature and its possible influence upon focal cerebral ischemia. Stroke 1982:13:759-66.

11 Haws $\mathrm{CH}$, Heistad DD. Effects of nimodipine on cerebral vasoconstrictor responses. Am F Physiol 1984;247: H170-6.

12 Grotenhuis JA, Bettag W, Fiebach BJO, Dabir K. Intracarotid slow bolus injection of nimodipine during angiography for treatment of cerebral vasospasm after subarachnoid hemorrhage. I Neurosurg 1984;61:231-40.

13 Ljunggren B, Brandt L, Saveland $\mathrm{H}$, et al. Outcome in 60 consecutive patients treated with early aneurysm operation and intravenous nimodipine. 7 Neurosurg 1984;61:864-73.

It Espinosa F, Weir B, Overton 'T, et al. A randomized placebo-controlled double-blind trial of nimodipine after subarachnoid hemorrhage in monkeys. I. Clinical and radiological findings. I Neurosurg 1984;61:231-40.

15 Nosko $M$, Weir B, Krueger C, et al. Nimodipine and chronic vasospasm in monkeys. I. Clinical and radiological findings. Neurosurgery 1985;16:129-36.

16 Philippon J, Grob R, Dagreou F, Guggiari M, Rivierez M, Viars P. Prevention of vasospasm in subarachnoid haemorrhage. A controlled study with nimodipine. Acta Neurochir (Wien) 1986;82:110-4.

17 Petruk KC, West M, Mohr G et al Nimodipine treatment in poor grade aneurysm patients. Results of a multicentre, double-blind, placebo grade aneurysm patients. Results of a multice

18 Gotoh O, Mohamed AA, McCulloch J, Graham DI Harper AM Teasdale GM. Nimodipine and the hemodynamic and histopathological consequences of middle cerebral artery occlusion in the rat. 7 Cereb Blood consequences of middle cer

19 Shaw MDM, Foy PM, Conway M, et al. Dipyridamole and post-operative ischemic deficits in aneurysmal subarachnoid hemorrhage. I Neurosur 1985;63:699-703.

20 Vermeulen $\mathrm{M}$, Lindsay $\mathrm{KW}$, Cheah $\mathrm{MF}$, et al. Antifibrinolytic treatment in subarachnoid hemorrhage. $N$ Engl f Med 1984;311:432-7.

21 Mohsen F, Pomonis S, Illingworth R. Prediction of delayed cerebral ischaemia after subarachnoid haemorrhage by computed tomography. I Neur: Neurosurg Psychiatry 1984;47:1197-202.

22 Auer LM. Acute operation and preventive nimodipine improve outcome in patients with ruptured aneurysms. Neurosurgery 1984;15:57-66.

23 Teasdale GM, Lindsay KW, Allardyce G, Dharker S, Ward P. Standardized clinical grading of paients with subarachnoid haemorrhage: a uniform clinical grading of patients with subarachnoid haemorrhage: a uniform international system? In. Auer

24 Teasdale GM. A universal subarachnoid haemorrhage scale: report of a committee of the World Federation of Neurosurgical Societies. I Neurol Neurosurg Psychiatry 1988;51:1457.

25 Jennett B, Bond $M$. Assessment of outcome after severe brain damage. A practical scale. Lancet $1975 ;$ i: $480-4$.
26 Gelmers $\mathrm{HJ}$, Gorter $\mathrm{K}$, de Weerdt $\mathrm{CJ}$, Wiezer HJA. A controlled trial of nimodipine in acute ischemic stroke. $N$ Engl f Med 1988:318:203-7.

7 Neil-Dwyer G, Mee E, Dorrance D, Lowe D. Early intervention with nimodipine in subarachnoid haemorrhage. Eur Heart $\mathcal{f}$ 1987;8 (suppl K): 41-7.

28 Ohman J, Heiskanen O. Effect of nimodipine on the outcome of patients after aneurysmal subarachnoid hemorrhage and surgery. I Neurosurg 1988;69: 683-6.

29 Jan M. Buchheit F, Tremoule M. Therapeutic trial of intravenous nimodipine in patients with established cerebral vasospasm after rupture of intracranial aneurysms. Neurosurgery 1988;23:154-7.

30 Vinge $\mathrm{E}$, Andersson KE, Brandt L, Ljunggren B, Nilsson LG, RosendalHelgesen S. Pharmacokinetics of nimodipine in patients with aneurysmal subarachnoid haemorrhage. Eur f Clin Pharmacol 1986;30:421-5.

31 Rämsch KD, Ahr G, Tettenborn D, Auer LM. Overview on pharmacokinetics of nimodipine in healthy volunteers and in patients with subarachnoid haemorrhage. Neurochirurgia (Stuttg) 1985;28(suppl 1):74-8.

32 Stulleken EH, Balestrieri FJ, Prough DS, McWhorter JM. The hemodynamic effects of mimodipine in patients anesthetised for cerebral aneurysm clipping. Anesthesiology 1985;62:346-8.

33 Merin RG. Calcium channel blocking drugs and anesthetics -is the drug interaction beneficial or detrimental? Anesthesiology 1987;66:111-3.

34 Tettenborn D, Dicka J, Volberg E, Düdden P. Blood pressure and heart rate during treatment with nimodipine in patients with subarachnoid rate during treatment with nimodipine in patients with

35 O'Neill P, West CR, Chadwick DW, et al. Post-ictal blood pressure in aneurysmal subarachnoid haemorrhage. Br f Neurosurg 1988;2:153-60.

36 Brandt L, Ljunggren B, Andersson KE, et al. Effects of topical application of a calcium antagonist (nifedipine) on feline cortical pial microvasculature under normal conditions and in focal ischemia. I Cereb Blood Flow Metabol $1983 ; 3: 44-50$

37 Takayasu M, Bassett JE, Dacey RG. Effects of calcium antagonists on intracerebral penetrating arterioles in rats. I Neurosurg 1988;69:104-9.

38 Middlemiss DN, Spedding $M$. A functional correlate for the dihydropyridine binding site in rat brain. Nature 1985;314:94-6.

39 Pickard JD, Walker V, Vile J, Perry S, Smythe PJ, Hunt R. Oral nimodipine reduces prostaglandin and thromboxane production by arteries chronically exposed to a periarterial haematoma and the antifibrinolytic agent tranexamic acid. $\mathcal{F}$ Neurol Neurosurg Psychiatry 1987;50:727-31

40 Phillis JW, O'Regan MH, Walter GA. Effects of nifedipine and felodipine on adenosine and inosine release from the hypoxemic rat cerebral cortex. ICereb Blood Flow Metab 1988;8:179-85.

41 Pickard JD, $\mathrm{Read} \mathrm{DH}$, Lovick $\mathrm{AHJ}$. Preoperative assessment of cerebrovascular reactivity following subarachnoid haemorrhage-clinical correlations. In: Auer LM, ed. Timing of aneurysm surgery. Berlin: Walter de Gruyter, 1985:47-51.

(Accepted 20 December 1988)

\section{Department of \\ Epidemiology, Erasmus \\ University Medical School, \\ Rotterdam, \\ The Netherlands \\ Jacqueline C M Witteman, \\ MSC, resident in epidemiology \\ Diederick E Grobbee, MD, \\ senior lecturer in epidemiology \\ Frans J Kok, PHD, senior \\ lecturer in epidemiology \\ Albert Hofman, MD, \\ professor of epidemiology \\ Hans A Valkenburg, MD, emeritus professor of \\ epidemiology}

Correspondence to:

Miss Witteman.

BrMed f 1989;298:642-4

\title{
Increased risk of atherosclerosis in women after the menopause
}

\author{
Jacqueline C M Witteman, Diederick E Grobbee, Frans J Kok, Albert Hofman, Hans A Valkenburg
}

Abstract

An increase in the incidence of cardiovascular disease has generally been observed in postmenopausal women, but there have been few studies of the association between menopausal state and atherosclerosis. In this study 294 premenopausal and 319 postmenopausal women aged 45 to 55 were examined radiographically for calcified deposits in the abdominal aorta, which have been shown to represent intimal atherosclerosis. Aortic atherosclerosis was present in eight $(3 \%)$ of the premenopausal women and in $38(12 \%)$ of the postmenopausal women. After adjustments for age and other indicators of cardiovascular risk women with a natural menopause had a 3.4 times greater risk of atherosclerosis than premenopausal women $(95 \%$ confidence interval 1.2 to $9.7 ; p<0.05$ ); women who had had a bilateral oophorectomy had a 5.5 times greater risk $(1.9$ to $15.8 ; p<0.005)$. No excess risk of atherosclerosis was observed among women who had had a hysterectomy without removal of both ovaries.

These results suggest that when oestrogen production stops, either naturally or after surgery, the risk of atherosclerosis is increased.

\section{Introduction}

An increase in the incidence of cardiovascular disease after the menopause has generally been observed, though not all studies agree with this finding. ${ }^{12}$ Non-invasive assessment of atherosclerosis may help to clarify this issue. Information on the extent of atherosclerosis in premenopausal and postmenopausal women has been gained mainly from necropsy studies. Compared with women with intact ovaries women who had had bilateral oophorectomy had an excess of coronary atherosclerosis, which approached that in men. ${ }^{34}$ We investigated the association between menopausal state and the presence of calcified deposits in the abdominal aorta as seen on lateral radiographs of the lumbar spine. The presence of such deposits represents true intimal atherosclerosis ${ }^{5}$ and is a strong predictor of death from cardiovascular causes. ${ }^{6}$

\section{Subjects and methods}

A population study on chronic diseases was conducted in Zoetermeer, a suburb of The Hague in The Netherlands, between 1975 and 1978. All inhabitants of one rural and one urban district who were aged 5 years and over were invited for a medical examination. The response rate among middle aged women was $77 \%$. Details of the initial study have been reported.' All women aged 45 to 55 without a history of cardiovascular disease $(n=676)$ were eligible for our study. The lower age limit was 45 because radiography of the lumbar spine was performed from this age onwards. The upper age limit of 55 was chosen to include sufficient premenopausal and postmenopausal women of similar ages.

We diagnosed atherosclerosis by radiographic detection of calcified deposits in the abdominal aorta. ${ }^{6}$ Lateral radiographs of the lumbar spine were available 
for $638(94 \%)$ of the women. Calcification was scored as definitely present when linear densities were clearly visible in an area parallel and anterior to the lumbar spine. No attempt was made to estimate the extent of atherosclerosis. Menopausal state was assessed by a self administered questionnaire. It asked whether the menses had stopped; if so, at what age; and the reason for them stopping (natural or artificial). The type of artificial menopause was ascertained during an interview by a doctor. No differentiation was made between hysterectomy alone and hysterectomy with unilateral oophorectomy. Menopause was defined as no menstruation for at least one year.

Twenty five women had last menstruated within one year before the examination, and these women were excluded from the analysis. This left 613 women, of whom 294 were premenopausal and 319 postmenopausal. In 178 women the menopause had occurred spontaneously, 73 had had a bilateral oophorectomy, and 55 had had a hysterectomy without removal of both ovaries. Other reasons for the menopause were reported by five women. Information on the type of artificial menopause was missing for eight women. Information on current use of postmenopausal oestrogens was obtained by a questionnaire and was checked during an interview. (Subjects were asked to take all current drugs on a visit to the research centre.) At the time of the study no information was collected on past use of postmenopausal oestrogens.

Blood pressure was measured in the sitting position with a random zero sphygmomanometer. Serum total cholesterol concentration was measured by an automated enzymatic method.' Body mass index was calculated as weight divided by height squared. Smoking behaviour was assessed by a self administered questionnaire.

TABLE I-Indicators of cardiovascular risk (adjusted for age) in premenopausal and postmenopausal women

\begin{tabular}{|c|c|c|}
\hline & $\begin{array}{c}\text { Premenopausal } \\
\text { women } \\
(n=294)\end{array}$ & $\begin{array}{l}\text { Postmenopausal } \\
\text { women } \\
(\mathrm{n}=319)\end{array}$ \\
\hline Mean (SE) age (years) & $49 \cdot 0(0 \cdot 1)$ & $51.9(0 \cdot 2)^{\star}$ \\
\hline $\begin{array}{l}\text { Mean (SE) systolic blood pressure } \\
(\mathrm{mm} \mathrm{Hg})\end{array}$ & $132 \cdot 9(1 \cdot 1)$ & $131 \cdot 5(1 \cdot 1)$ \\
\hline $\begin{array}{l}\text { Mean (SE) diastolic blood pressure } \\
(\mathrm{mm} \mathrm{Hg})\end{array}$ & $82 \cdot 3(0 \cdot 7)$ & $82 \cdot 6(0 \cdot 7)$ \\
\hline Mean (SE) serum total cholesterol & $5 \cdot 9(0 \cdot 1)$ & $6 \cdot 3(0 \cdot 1)^{\star}$ \\
\hline Mean (SE) body mass index $\left(\mathrm{kg} / \mathrm{m}^{\prime}\right)$ & $25 \cdot 1(0 \cdot 2)$ & $25 \cdot 3(0 \cdot 2)$ \\
\hline No $(\%)$ current smokers & $111(38)$ & $144(45)$ \\
\hline No $(\%)$ past smokers & $82(28)$ & $76(24)$ \\
\hline No $(\%)$ with diabetes mellitus & $8(3)$ & $4(1)$ \\
\hline
\end{tabular}

${ }^{\star} \mathrm{p}<0 \cdot 001$.

TABLE II-Relative risks of aortic calcification in premenopausal and postmenopausal women by type of menopause for two age groups and for both age groups combined

\begin{tabular}{|c|c|c|c|c|}
\hline Type of menopause & $\begin{array}{l}\text { No with } \\
\text { aortic calcification }\end{array}$ & Relative risk & $\begin{array}{c}95 \% \\
\text { Confidence interval }\end{array}$ & p Value \\
\hline \multicolumn{5}{|c|}{ Women aged 45 to 50} \\
\hline Premenopausal & $6 / 235$ & $1 \cdot 0$ & & \\
\hline Natural & $3 / 33$ & $3 \cdot 8$ & $(0 \cdot 9-16 \cdot 1)$ & \\
\hline Induced by bilateral oophorectomy & $6 / 43$ & $6 \cdot 2$ & $(1 \cdot 9-20 \cdot 3)$ & $<0.001$ \\
\hline Induced by hysterectomy ${ }^{\star}$ & $0 / 31$ & & & \\
\hline \multicolumn{5}{|c|}{ Women aged 51 to 55} \\
\hline Premenopausal & $2 / 59$ & $1 \cdot 0$ & & \\
\hline Natural & $20 / 145$ & $4 \cdot 5$ & $(1 \cdot 0-20 \cdot 2)$ & $<0.05$ \\
\hline Induced by bilateral oophorectomy & $6 / 30$ & $7 \cdot 1$ & $(1 \cdot 3-37 \cdot 8)$ & $<0.01$ \\
\hline Induced by hysterectomy ${ }^{\star}$ & $1 / 24$ & $1 \cdot 2$ & $(0 \cdot 1-14 \cdot 3)$ & \\
\hline \multicolumn{5}{|c|}{ All women $\dagger$} \\
\hline Premenopausal & $8 / 294$ & $1 \cdot 0$ & & \\
\hline Natural & $23 / 178$ & $4 \cdot 3$ & $(1 \cdot 4-12 \cdot 9)$ & $<0.01$ \\
\hline Induced by bilateral oophorectomy & $12 / 73$ & $6 \cdot 6$ & $(2 \cdot 5 \cdot 17 \cdot 1)$ & $<0.001$ \\
\hline Induced by hysterectomy* & $1 / 55$ & 0.6 & $(0 \cdot 1-5 \cdot 4)$ & \\
\hline
\end{tabular}

*Includes women with unilateral oophorectomy.

†Relative risks adjusted for age group by method of Mantel-Haenszel.
DATA ANALYSES

Characteristics of the premenopausal and postmenopausal women were adjusted for age by direct standardisation (categorical variables) and by analysis of covariance (continuous variables). Differences in group means were tested by two tailed $t$ tests. Odds ratios with confidence intervals derived according to Woolf's method ${ }^{8}$ were used as an approximation of relative risks for comparison of premenopausal and postmenopausal women and of types of menopause. After stratification by age Mantel-Haenszel odds ratios were calculated with Miettinen's test based confidence intervals. ${ }^{8}$ Multivariate analysis was used to adjust for age (one year categories) and other indicators of cardiovascular risk. Logistic regression coefficients and their standard errors were estimated by the method of maximum likelihood, ${ }^{8}$ from which adjusted estimates of relative odds with $95 \%$ confidence intervals were calculated to approximate relative risk. If the $95 \%$ confidence interval did not include the value one the risk estimate was regarded as significant. Trends in relative risk for categories of postmenopausal years were tested by the Mantel test for trend. ${ }^{8}$

\section{Results}

The postmenopausal women were significantly older than the premenopausal women (table I). There was, however, a reasonable overlap in age between the two groups: below the first quintile of age $147(24 \%)$ of the women were postmenopausal; above the fourth quintile $55(9 \%)$ were premenopausal. When the characteristics of the women were adjusted for age significant differences between the two groups were found only for serum total cholesterol concentration (table I). The characteristics of the women who had had a natural menopause, women who had had a bilateral oophorectomy, and women who had had a hysterectomy without removal of both ovaries were not significantly different, except for mean age $(52 \cdot 9,50 \cdot 7$, and 50.5 years respectively) and mean number of postmenopausal years $(4 \cdot 6,7 \cdot 2$, and $7 \cdot 6$ respectively). Eight $(3 \%)$ of the premenopausal and $38(12 \%)$ of the postmenopausal women had aortic calcification. Table II gives the numbers of women with aortic calcification according to the type of menopause for those aged 45-50 and those aged 51-55. Estimates of relative risks did not differ significantly between the age groups. Although significantly raised risks were found for women after a natural menopause or bilateral oophorectomy, no excess risk was observed for women after a hysterectomy without removal of both ovaries. Women with other reasons for the menopause or missing information $(n=13)$ were excluded from the analysis.

Because age categories of five years may be too broad to adjust adequately for age effects logistic regression analysis was used, with age as a continuous variable. Simultaneous adjustment for age and other indicators of cardiovascular risk, however, resulted in only small changes in the estimated risks: women with a natural menopause had a 3.4 times greater risk of aortic calcification than premenopausal women ( $95 \%$ confidence interval 1.2 to $9.7 ; \mathrm{p}<0.05$ ), and women who had had a bilateral oophorectomy had a 5.5 times greater risk $(1.9$ to $15.8 ; \mathrm{p}<0.005)$. The relative risk for women who had had a bilateral oophorectomy was 1.7 times the risk for women who had had a natural menopause, but this was not significant ( $95 \%$ confidence interval $0 \cdot 7$ to $4 \cdot 4$ ).

Other variables that were significantly associated with the risk of aortic calcification were smoking and serum total cholesterol concentration. Current smokers had a 4.8 times greater risk of aortic calcification than women who had never smoked (1.9 to $11.7 ; \mathrm{p}<0.001)$. 


\begin{tabular}{|c|c|c|c|c|c|c|}
\hline \multirow[b]{2}{*}{$\begin{array}{l}\text { No of years } \\
\text { after menopause }\end{array}$} & \multicolumn{3}{|c|}{ Natural menopause } & \multicolumn{3}{|c|}{ Bilateral oophorectomy } \\
\hline & $\begin{array}{c}\text { No with } \\
\text { aortic calcification }\end{array}$ & Relative risk ${ }^{\star}$ & $\begin{array}{c}95 \% \\
\text { Confidence interval }\end{array}$ & $\begin{array}{l}\text { No with } \\
\text { aortic calcification }\end{array}$ & Relative risk & $\begin{array}{c}95 \% \\
\text { Confidence interval }\end{array}$ \\
\hline $\begin{array}{l}\text { Premenopausal } \\
1-4 \\
5-8 \\
>8\end{array}$ & $\begin{array}{c}8 / 294 \\
11 / 107 \\
6 / 43 \\
6 / 28\end{array}$ & $\begin{array}{l}1 \cdot 0 \\
2 \cdot 9 \\
5 \cdot 1 \\
7 \cdot 1\end{array}$ & $\begin{array}{l}0.9 \text { to } 9.5 \\
1.2 \text { to } 22.7 \\
1.5 \text { to } 33.0+\end{array}$ & $\begin{array}{l}8 / 294 \\
3 / 23 \\
5 / 26 \\
4 / 24\end{array}$ & $\begin{array}{l}1 \cdot 0 \\
6 \cdot 0 \\
8 \cdot 4 \\
5 \cdot 6\end{array}$ & $\begin{array}{l}1.3 \text { to } 28.0 \\
2.0 \text { to } 36.0 \\
1.3 \text { to } 23.6\end{array}$ \\
\hline
\end{tabular}

*Adjusted for age and other indicators of cardiovascular risk.

$\nmid$ Mantel test for trend: $\chi^{2}=17 \cdot 9 ; p<0 \cdot 001$.

An increase in serum cholesterol concentration of $1 \mathrm{mmol} / \mathrm{l}$ was associated with a 1.8 times greater risk of aortic calcification $(1.3$ to $2 \cdot 4 ; \mathrm{p}<0.001)$. An increase in systolic blood pressure of $20 \mathrm{~mm} \mathrm{Hg}$ was associated with a 1.5 times greater risk, but this was not significant $(0.9$ to $2 \cdot 5)$. No associations with risk of aortic calcification were found for diastolic blood pressure, body mass index, or diabetes mellitus.

Among women with a natural menopause the risk of aortic calcification adjusted for age and other indicators of cardiovascular risk showed a highly significant trend $(\mathrm{p}<0.001)$ with increasing years after the menopause. The findings among women who had had a bilateral oophorectomy were less clear (table III).

Postmenopausal oestrogens were being taken by three of the 25 women (12\%) who had last menstruated within one year before the study and by $14(4 \%)$ who had last menstruated more than one year before the study. Aortic calcification was observed in one of these 17 women.

\section{Discussion}

We found a strong association between the menopause, induced either naturally or surgically, and the presence of calcified deposits in the abdominal aorta. Before any inferences can be drawn from our findings the importance of calcification in the aorta needs to be considered. The validity of radiographic assessment of aortic calcification in the diagnosis of atherosclerosis has been studied by comparison with assessments made on necropsy material. ${ }^{5}$ The method was shown to be highly specific, and in most cases visible calcification represented advanced atherosclerosis. Thus in some of our subjects minor and intermediate stages of atherosclerosis may have been present but not seen; if they had been seen the relative risks would have been even higher. Our observations that serum cholesterol concentration and smoking were strongly associated with aortic calcification further indicate that we were measuring intimal atherosclerosis.

Arteries may vary in their susceptibility to menopausal influences on atherosclerosis, and our results may thus not be extended to the risk of coronary atherosclerosis. Aortic calcification, however, is strongly associated with cardiovascular disease, ${ }^{69}$ and this association, whether mediated by concomitant atherosclerosis in other vessel beds or not, emphasises the importance of our findings.

Whether hysterectomy without removal of both ovaries leads to an increased risk of cardiovascular disease is disputable. ${ }^{12}$ Our results do not confirm an atherosclerotic effect of hysterectomy and suggest that the acceleration of atherosclerosis with the menopause occurs after oestrogen production stops. Some of our subjects may not have been able to report the exact nature of their surgery. If, however, some misclassification did take place the true difference in atherosclerotic risk between women who had had hysterectomies and women who had had bilateral oophorectomy would be even more pronounced.

The trend in the risk of atherosclerosis with the number of postmenopausal years, which was seen among women with a natural menopause, suggests a causal relation. The findings among women with bilateral oophorectomy, however, were less clear. The number of women taking postmenopausal oestrogens was too small for analysis. Use of replacement oestrogens has always been fairly low in The Netherlands. At the time of the study replacement oestrogens were used by about $10 \%$ of Dutch perimenopausal women (International Health Foundation, Brussels, unpublished observations).

Serum total cholesterol concentration was significantly higher among the postmenopausal women, which agrees with previous findings. ${ }^{10}$ The effect of the menopause on atherosclerosis, however, could only partly be explained by changes in serum cholesterol concentration or other indicators of cardiovascular risk. Possibly, therefore, oestrogens have a direct effect on the vessel wall, as has been seen in animals. ${ }^{.1}$

Our findings suggest a strongly increased rate of atherosclerosis after ovarian involution. Whether this increased rate can be limited to some extent by use of postmenopausal oestrogens remains to be ascertained.

This work was supported by The Netherlands Organisation for the Advancement of Pure Research.

1 Kannel WB, Hjortland MC, McNamara PM, Gordon T. Menopause and risk of cardiovascular disease. The Framingham study. Ann Intern Med 1976;85 447-52.

2 Colditz GA, Willett WC, Stampfer MJ, Rosner B, Speizer FE, Hennekens $\mathrm{CH}$. Menopause and the risk of coronary heart disease in women. $N \mathrm{Engl}$ Med 1987;316:1105-10.

3 Wuest JH, Dry TJ, Edwards JE. The degree of coronary atherosclerosis in bilaterally oophorectomized women. Circulation 1953;7:801-9.

4 Rivin AU, Dimitroff SP. The incidence and severity of atherosclerosis in estrogen-treated males, and in females with a hypoestrogenic or a in estrogen-treated males, and in females

5 Hyman JB, Epstein FH. A study of the correlation between roentgenographic and post-mortem calcification of the aorta. Am Heart $\mathcal{F}$ 1954;47:540-3.

6 Witteman JCM, Kok FJ, Saase van JLCM, Valkenburg HA. Aortic calcification as a predictor of cardiovascular mortality. Lancet 1986;ii: $1120-2$

7 Valkenburg HA, Hofman A, Klein F, Groustra FN. An epidemiological study of cardiovascular risk indicators (EPOZ). I. Blood pressure, serum cholesterol level, Quetelet's index and smoking habits in an open population aged 5 years and over. Ned Tijdschr Geneeskd 1980;124:183-9. (In Dutch.)

8 Schlesselman JJ. Case-control studies. Design, conduct, analysis. Oxford: Oxford University Press, 1982

9 Eggen DA. Relationship of calcified lesions to clinically significant atherosclerotic lesions. Ann NY Acad Sci 1968; 149:752-67.

0 Baird DD, Tyroler HA, Heiss G, Chambless LE, Hames CG. Menopausal change in serum cholesterol. Black/white differences in Evans County Georgia. Am $\mathcal{F}$ Epidemiol 1985;122:982-93.

11 Fischer-Dzoga K, Wissler RW, Vesselinovitch D. The effect of estradiol on the proliferation of rabbit aortic medial tissue culture cells induced by the proliferation of rabbit aortic medial tissue culture
hyperlipemic serum. Exp Mol Pathol 1983;39:355-63.

(Accepted 28 December 1988)

\section{Correction}

Prevention of atherosclerotic complications: controlled trial of ketanserin

An editorial error occurred in this paper by the Prevention of Atherosclerotic Complications with Ketanserin Trial Group (18 February, p 424) after the proof stage. The third sentence of the measurements and main results section of the abstract was changed and "were included" was substituted for the original "exclusion of." The sentence should have read: "After patients taking potassium losing diuretics or antiarrhythmic agents were excluded a secondary analysis. . . ." 